\title{
Skill-centered Teaching in the Accounting Classroom
}

\section{INTRODUCTION}

The debate between content-based and skill-based teaching has been here for a long time that runs through the education chain from $\mathrm{K}$ to 12 until higher education. It is to a large extent also phrased as a debate between breadth and depth. Often times, it is presented as a zero-sum game - if you want to cover more materials in class (breadth), then it is hard to cover in more depth because the tactics that promote deep learning are simply time-consuming. The debate goes on without much consensus.

In this paper, I argue the necessity and feasibility of developing an accounting classroom centered on enhancing multi-skills simultaneously in this digital age. The skill-centered teaching should be integrated with in-depth learning of discipline-based fundamental concepts and theories. Skills in this paper refer to the skills of processing contents, technical skills including technology proficiency and soft skills such as communication and teamwork. I also discuss different ways to develop such a skill-centered accounting classroom.

\section{WHY A SKILL-CENTERED CLASSROOM}

There are several reasons that it is time to develop a skill-centered classroom. First, delivery of contents in simply not enough and sometimes not even necessary any more. In this digital age, contents are readily available online or can be made available online at low cost or even for free. A simple Google search generates tons of materials on a topic delivered in a variety of formats lecture notes, PowerPoint, videos, games and even one-on-one tutoring service. For more systematic introduction to a subject area, online teaching platform such as Coursera.com or YouTube channels provide many choices. For example, a simple search on Coursera.com with "accounting" as the key word generate 247 courses ranging from fundamentals in financial accounting to trendy courses such as accounting data analytics with python as of March 19, 2020. As of July 24 2020, when I updated this paper, it jumps to 409 total results. A search of the term "accounting analytics" generates 256 total results. Second, students' learning behaviors have changed dramatically in the past few years thanks to the proliferation in digital devices and contents. I have seen a significant drop in attention and patience. Students' overall skills of decoding text seem to be deteriorating as well. Simple delivery of contents in the form of lectures is very hard to gain traction in students' mind. The rapidly changing business environment and technological development also put pressure on students and basically everybody to update their knowledge on a constant basis. Therefore, enhancing the skill to process contents is more important. We need to give students the skill of fishing, not give them fish as the saying goes. All in all, it is necessary to switch to skill-centered teaching in the accounting classroom.

The skill-centered classroom should be built upon discipline-specific fundamentals. The reason is that different disciplines require different sets of skills, albert the existence of overlapping. Even for general skill like critical thinking, it is argued that it is contextual and intimately tied to the 
particular subject matter with which one is concerned. This integration also allows students to dive deeper in understanding accounting concepts and theories that have broader applications.

\section{HOW TO BUILD A SKILL-CENTERED CLASSROOM}

Promotion of skill-centered classroom does not mean that the breadth of knowledge is not important any more. Instead, the breadth of knowledge can be obtained outside of the classroom. The responsibility for a professor is to point to the right direction and organize the materials in an accessible way so students can study on their own taking advantage of the different types of resources available. The abundance of multimedia contents makes guided self-learning possible and efficient. Another responsibility for a professor is to provide assessment to help students identify trouble spots, which will be explained further and built into the in-depth study in class. Multiple-choice questions, true and false questions and matching questions are easier to test students' understanding of basic concepts. Quiz applications such as Socrative and learning management system (LMS) could be well used here. Discussion questions built into the discussion forum of LMS can be used to motivate students' thinking and engaging in dialogue. All can be well done outside of the classroom.

The next question is what skills should be developed inside the accounting classroom. If we ask a college freshman why he chooses accounting as major, often time the answer is "I think I am good at math". Accounting students, however, need more than just quantitative skills. They need to develop a variety of skills that are essential for a successful career. First, given the important role accounting plays in users' decision making, critical thinking and analytical skills are equally important as the quantitative skills. Second, the skill to process contents which include how to synthesize information, how to identify trouble spots and how to resolve trouble spots. Another skill is to practice elaboration and make connection, as argued in the book "Make It Stick, The Science of Successful Learning”. It says “... if you practice elaboration, there's no known limit to how much you can learn. ... The more you can explain about the way your new learning relates to your prior knowledge, the stronger your grasp of the new learning will be, and the more connections you create that will help you remember it later."

Accountants need to be good communicators which demand strong writing and presentation skills. Social skills and teamwork are other skills that are essential for accountants, especially auditors. Technically, proficiency in technology, especially tools to analyze data is essential. As the progression of careers, skills of negotiation and persuasion are gaining importance as well.

As to how to build a skill-based classroom, the approach might vary across different areas of accounting. In general, the use of case studies has long been advocated. CPA firms such E\&Y and KPMG have their own educational resources that offer rich cases, so do some accounting organizations such as IMA and Center for Audit Quality. For financial accounting and auditing, Deloitte Trueblood Case Study Series provide a number of excellent cases that offer a context to have in-depth learning of many topics while practicing multi-skills at the same time, including analyzing a complex scenario, researching the accounting standard, presenting research results, exercising their professional judgment to draw a conclusion and finally delivering their research, 
analysis, and conclusion in a memo format. Students can also share real-world cases from newspaper, similar to the opening stories available in textbooks, and discuss how it is related to the course content. Comprehensive and integrated cases normally have the advantage of enabling students to see a big picture and the connection. Short seminars on technical skill development and soft skill development but in the context of accounting can be offered along the way.

Proficiency in technology can be integrated with teaching fundamental concepts, theories and analyses. For example, the entire topics of managerial accounting can be covered in an Excel environment. The hands-on approach is better at keeping students' attention and giving them a sense of fulfillment and therefore a deeper understanding of the content. For auditing, students can learn sampling techniques, and risk analysis through learning how to use IDEA or ACL, the audit analytics tools. For Accounting Information System, the concepts of internal controls are better illustrated through the learning of QuickBooks or NetSuite, and Microsoft Access database. All can be done in a team setting. The skill-based and experience rich approach makes learning more fun, facilitates a learning community and gives students a deeper understanding of the concepts at the same time.

\section{CONCLUSION}

To conclude, in this article, I argue that a skill-centered classroom built upon in-depth learning of discipline-based contents becomes a necessity in this digital age. I cover the important skills that

are required of accounting professionals and suggest a few ways for them to be developed in the accounting classroom.

\section{REFERENCES}

Brown, Peter, C. Make It Stick: The Science of Successful Learning. Belknap Press: An Imprint of Harvard University Press

Gooblar, David. "Skills First, and Let Content Follow." The Chronicle of Higher Education. September 21, 2016. Accessed July 25, 2020. https://community.chronicle.com/news/1551-skills-first-and-let-content-follow

Data Driven: What Students Need to Succeed in a Rapidly Changing Business World. PwC. February 2015. Accessed July 25, 2020. https://www.pwc.com/us/en/facultyresource/assets/pwc-data-driven-paper-feb2015.pdf

Schueler, John. “Inside Higher Ed.” Insider Higher Ed. June 7, 2016. Accessed July 25, 2020. https://www.insidehighered.com/views/2016/06/07/can-colleges-truly-teach-criticalthinking-skills-essay. 